H. LI, X. JIANG, Y.-H. YE, C. FAN, T.ROMOFF, M. GOODMAN* (UNIVERSITY OF

CALIFORNIA AT SAN DIEGO, USA AND PEKING UNIVERSITY, BEIJING, P. R. OF CHINA)

3-(Diethoxyphosphoryloxy)-1,2,3-benzotriazin-4(3H)-one (DEPBT): A New Coupling Reagent with Remarkable Resistance to Racemization

Org. Lett. 1999, 1, 91-93, DOI: 10.1021/ol990573k.

\section{Phosphate-Reagent-Mediated Peptide Coupling Reactions}

Preparation of the coupling reagent:

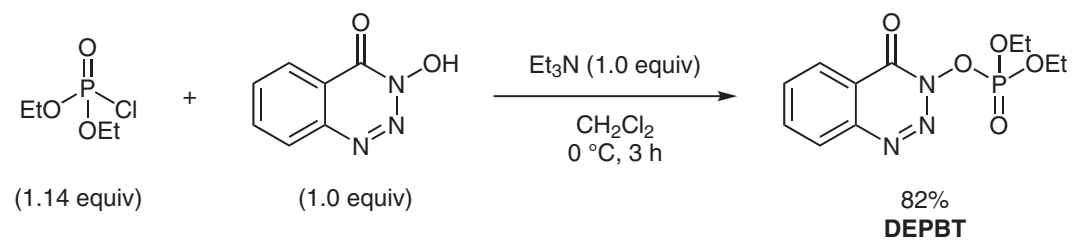

Selected examples for peptide coupling reactions:<smiles>COC(=O)[C@H](N)Cc1ccccc1</smiles>

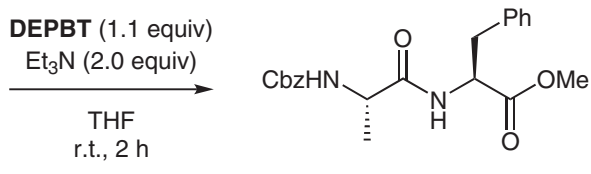

$94 \%$ yield<smiles>CC[C@H](C)[C@H](NC(=O)OCc1ccccc1)C(=O)O</smiles><smiles>COC(=O)[C@H](N)Cc1ccc(O)cc1</smiles>

DEPBT (1.1 equiv) $\mathrm{Et}_{3} \mathrm{~N}(2.0$ equiv $)$ THF
r.t., $2 \mathrm{~h}$<smiles>CCCCOC(=O)N[C@@H](C(=O)N[C@@H](Cc1ccc(O)cc1)C(=O)OC)C(C)C</smiles>

$91 \%$ yield<smiles>CC(C)(C)OC(=O)N[C@@H](Cc1c[nH]c2ccccc12)C(=O)O</smiles><smiles>COC(=O)CNC(=O)CNC(=O)[C@H](N)CCCCNC(C)=O</smiles>

DEPBT ( 1.1 equiv) $\mathrm{Et}_{3} \mathrm{~N}$ (2.0 equiv)

DMF r.t., $4 \mathrm{~h}$<smiles>COC(=O)CNC(=O)CNC(=O)[C@H](CCCCNC(=O)OCc1ccccc1)NC(=O)[C@H](Cc1c[nH]c2ccccc12)NC(=O)OCc1ccccc1</smiles>

Category

Peptide Chemistry

\section{Key words}

peptide bond formation

coupling

phosphate reagent
Significance: Peptide coupling reagents are extremely important in peptide synthesis. In 1999, Goodman and co-workers reported the development of the phosphate reagent 3-(diethoxyphosphoryloxy)-1,2,3-benzotriazin-4(3H)-one (DEPBT) as a coupling reagent that can be easily prepared from diethyl chloridophosphate and 3-hydroxy1,2,3-benzotriazin-4(3H)-one.
Comment: By using DEPBT as a coupling reagent, various peptides can be synthesized in excellent yields. 